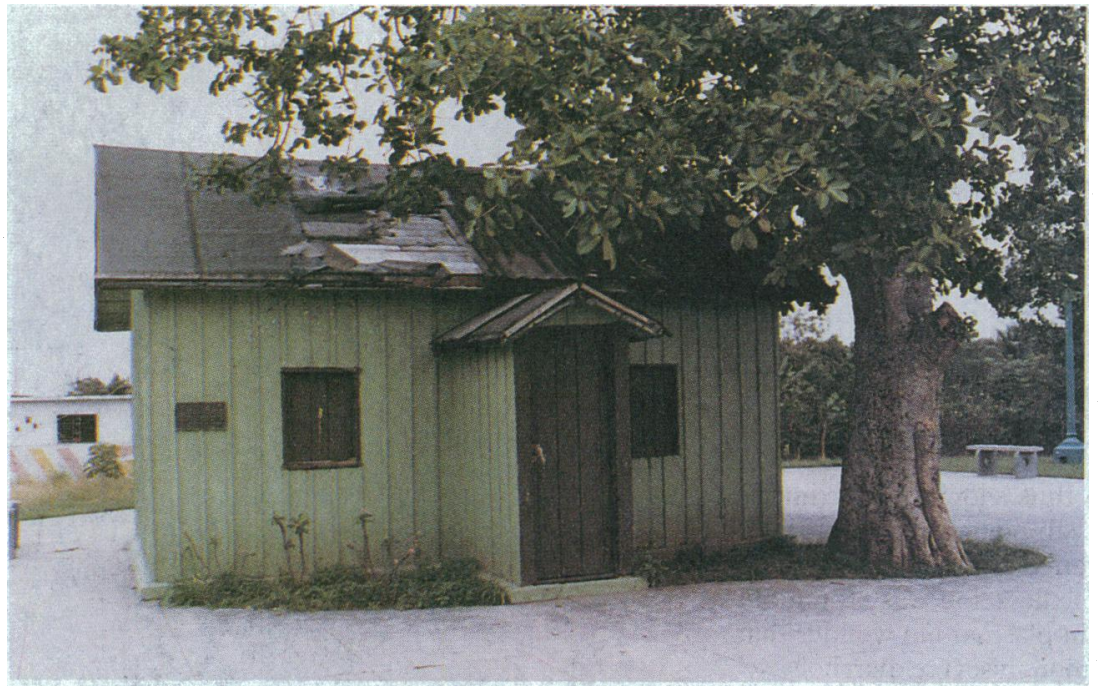

Finlay's laboratory, Parque Lazear, Havana on 21 May. W A Young, a British pathologist in Accra who had been working with Noguchi, also died of yellow fever on 29 May.

Several writers have suggested that Noguchi, having accepted that he had been mistaken, deliberately infected himself with yellow fever as a form of scientific hari kari. Philip dismisses this suggestion, believing that a laboratory accident was much more likely. On his way to Lagos Philip left the ship for a few hours in Accra to visit the Medical Research Institute but found Noguchi asleep, having worked all night, as he frequently did to avoid other members of the laboratory. Philip had intended to take some infected mosquitoes from Accra to Lagos but on inspecting the cages found so many holes through which mosquitoes might escape that he decided not to take any. Plesset concurs with the view that conditions in Noguchi's laboratory were chaotic. ${ }^{16}$ Philip was aware of the hazard of being bitten by an infected mosquito, and when this happened to him in his own mosquito house in Lagos he was immediately injected with convalescent serum preserved with tricresol, which may well have saved his life. Haynes who came out to Lagos to relieve Philip, was less fortunate and died of yellow fever, almost certainly acquired in the same manner.
Although in 1902 Gorgas looked forward to the disappearance of yellow fever after the control of $A$ aegypti, the emergence of jungle yellow fever with an entirely different vector species dashed his hopes. There is no prospect that yellow fever can be eradicated in the same way as smallpox. The control of aedes is still important in limiting yellow fever in urban areas, but vaccination provides the best safeguard. The people who died in the yellow fever epidemics in Nigeria in 1986 and 1987 were unvaccinated, apart from one peron who had received $17 \mathrm{D}$ vaccine only five days previously, too short an interval to be protective. Asibi's yellow fever was mild, and he made a complete recovery. In the 1950 s he was traced by the medical authorities in the Gold Coast and was given a pension by the Colonial Office to commemorate his part in the epic history of the control of yellow fever. Sadly, that control is all too commonly absent in parts of the world where it is most needed.

I thank Dr C B Philip, whose comments and letters are largely responsible for the writing of this article.

1 DeCock KM, Monath TP, Nasidi A, et al. Epidemic yellow fever in Eastern Nigeria, 1986. Lancet 1988;i:630-3.

2 Nasidi A, Monath TP, DeCock KM, et al. Urban yellow fever epidemic in Western Nigeria, 1987. Trans $R$ Soc Trop Med Hyg 1989;83:401-6.

3 Theiler $M$, Smith $\mathrm{HH}$. Use of yellow fever virus modified by in vitro cultivation for human immunization. $\mathcal{F} \operatorname{Exp}$ Med 1937;65:787-800

4 Stokes A, Bauer JH, Hudson NP. Experimental transmission of yellow fever to laboratory animals. Am 7 Trop Med 1928;8:103-64.

5 Strode GK. Yellow fever. New York: McGraw Hill, 1951:1-710.

6 Carter HR. Yellow fever, an epidemiological and historical study of its place of origin. Baltimore: Williams and Wilkins, 1931.

7 Blake JB. Symposium on American contributions to the history of tropical medicine. Bull NY Acad Sci 1968;44:621-754.

8 Theiler M. Yellow fever. In: Rivers TM, ed. Viral and ricketsial infections of man. 2nd ed. Philadelphia: Lippincott, 1952:531-51.

9 Smith CEG, Gibson CE. Yellow fever in South Wales, 1865. Med Hist 1986;30:322-40.

10 Meers PD. Yellow fever in Swansea, 1865. J Hygiene 1986;97:185-91.

11 Bean WB. Walter Reed: a biography. Charlottesville: University Press of Virginia, 1982

12 Reed W, Carroll J. Etiology of yellow fever: supplemental note. American Medicine 1902;3:301-5.

13 Noguchi H. Etiology of yellow fever; transmission experiments on yellow fever. $\mathcal{E}$ Exp Med 1919;29:565-84.

14 Noguchi H. Yellow fever research, 1918-1924: summary Leptospira icteroides. f Trop Med 1925;28:185-93.

15 Noguchi H. Spirochaeta icterohaemorrhagiae in American wild rats and its relation to the Japanese and European strains. $\mathcal{J}$ Exp Med 1917;25:755-63.

16 Plesset IR. Noguchi and his patrons. Cranbury, New Jersey: Associated University Presses, 1980

17 Anonymous. Report from Paris. Lancet 1927;i:1265.

18 Hudson NP. Adrian Stokes and yellow fever research: a tribute. Trans $R$ So Trop Med Hyg 1966;60:170-4.

\section{Bramhope, Leeds LS16 9JD \\ Frank M Parsons, FRCP retired consultant in renal medicine \\ Dr Parsons, formerly consultant renal physician and senior lecturer in medicine at the University of Leeds until his retirement in 1983, died on 17 August (Obituary, 2 December, p 1396).}

Br Med f 1989;299:1557-60

\title{
Origins of haemodialysis in the United Kingdom
}

\author{
Frank M Parsons
}

I qualified in medicine in 1943 at the University of Leeds, having obtained a BSc with honours in physiology on the way. After working for three years as a house surgeon and demonstrator in physiology I took the primary FRCS examination and joined the Royal Army Medical Corps as a graded surgeon. I was demobbed in the summer of 1949, a year after the start of the NHS. Having learnt the new terminology of the hospital medical staff and noted an administrator at every corner, I was appointed registrar to $\mathrm{Mr}$ Pyrah - a lucky choice as he was one of the foremost surgeons in Leeds and had an interest in urology.

The next sumimer after I returned from holiday a serious outbreak of infection caused by Pseudomonas aeruginosa occurred in the prostate ward. An open system of bladder drainage was then in use and the pathologist, Dr Goldie, soon traced the source to large tanks filled with Dettol in which the urinals were placed for "sterilisation." I changed this to a closed system of bladder drainage which was fully autoclavable, including the drainage bottles. The result was dramatic: urine remained sterile for weeks even with continued bladder drainage. In the 1930s and early 'forties prostatectomy had a mortality of $70 \%$ because the new closed methods of prostatectomy with a mortality of less than $10 \%$ were not commonly used. Patients with prostate problems therefore tended to keep their prostates as long as possible, eventually being admitted with urinary retention that required drainage of the bladder. My development of a closed drainage system encouraged Mr Pyrah to build up a research department, and beforè long I was appointed research fellow in urology at the University of Leeds by the vice chancellor, Mr Pyrah, the professor of surgery, and the registrar of the university - the "top brass" of the university appointing the lowest of the 
low. The professor of surgery thought that I should continue with surgery, but he did not live long enough to learn how wrong he had been.

My first research topic was to unravel the biochemical imbalance occurring after ureterocolic anastomosis, given that a hyperchloraemic acidosis was known to occur. Luck soon came my way for I acquired and operated the first flame photometer for estimating sodium and chloride ion concentrations to be installed in Yorkshire. With this and the help of Professor Spiers and his staff in the department of medical physics the problem was soon solved - it was a differential reabsorption of chloride in the colon that was not accompanied by an equivalent reabsorption of sodium. The treatment was thus a low chloride intake with sodium bicarbonate supplementation. I later found that potassium depletion also occurred as the equilibrium in the lumen of the colon was $40 \mathrm{mmol} / \mathrm{l}$ compared with 4-5 mmol/l in plasma. No wonder that potassium depletion is common in severe diarrhoea.

With the availability of the flame photometer I could move ahead fast, but I had nobody to help me in Leeds. In those early days published work was little help and I had to teach myself the rudiments of fluid and electrolyte balance, relying on my basic physiological training. With the kidneys knocked out, accuracy in replacement was essential. Soon I was being asked to look after patients with acute tubular necrosis. The introduction of the Bull dieting regimen $-200 \mathrm{kcal}$ $(837 \mathrm{~kJ})$ and 1 litre of water daily - was a gigantic leap forward, enabling us to say goodbye to sodium sulphate infusions, decapsulating kidneys, old remedies, and fluid overload. Even with this dietary regimen, however, it was touch and go whether the uraemia or the returning renal function would win, and when severe trauma or infection was present lethal uraemia would develop by the sixth day. On witnessing such a case for the first time I felt dejected and disillusioned and retired to the library to read Dr Merrill and colleagues' experience with an artificial kidney. The answer was obvious. We had to get an artificial kidney. But what chance had an unknown man, a mere research fellow, of altering the entrenched position against dialysis in the United Kingdom? Luck soon came my way again. Professor Pyrah had invited Professor Huggins in Chicago to address the annual meeting of the British Association of Urological Surgeons in Leeds and to receive an honorary degree. His "thank you" was to award me an American cancer research fellowship for a year. (Professor Huggins later received a Nobel prize and advocated orchidectomy in the treatment of cancer of the prostate and adrenalectomy in that of cancer of the breast.)

\section{4 in America}

Professor Huggins believed that he could cure recurrent cancer of the breast by endocrine manipulation and worked like a beaver on a cat model to achieve this. Naturally I was incorporated into this scheme, but it was far removed from renal failure. Professor Huggins sensed this and dispatched me to Professor Moore at Boston to learn about dialysis. I arrived at the Peter Bent Brigham Hospital the day after a terrific hurricane had struck trees down and immersed cars in lakes that had miraculously appeared overnight. I immediately realised that I had arrived in a unique institution - the happiest hospital that I was privileged to join. I was soon introduced to Dr Merrill, who warned me that I would have to work hard as he considered that it took a year to train a person in dialysis and I had less than four months. Work hard I did, helped enormously by his friendly and expert staff.

A few weeks before I left Dr Merrill told me that I

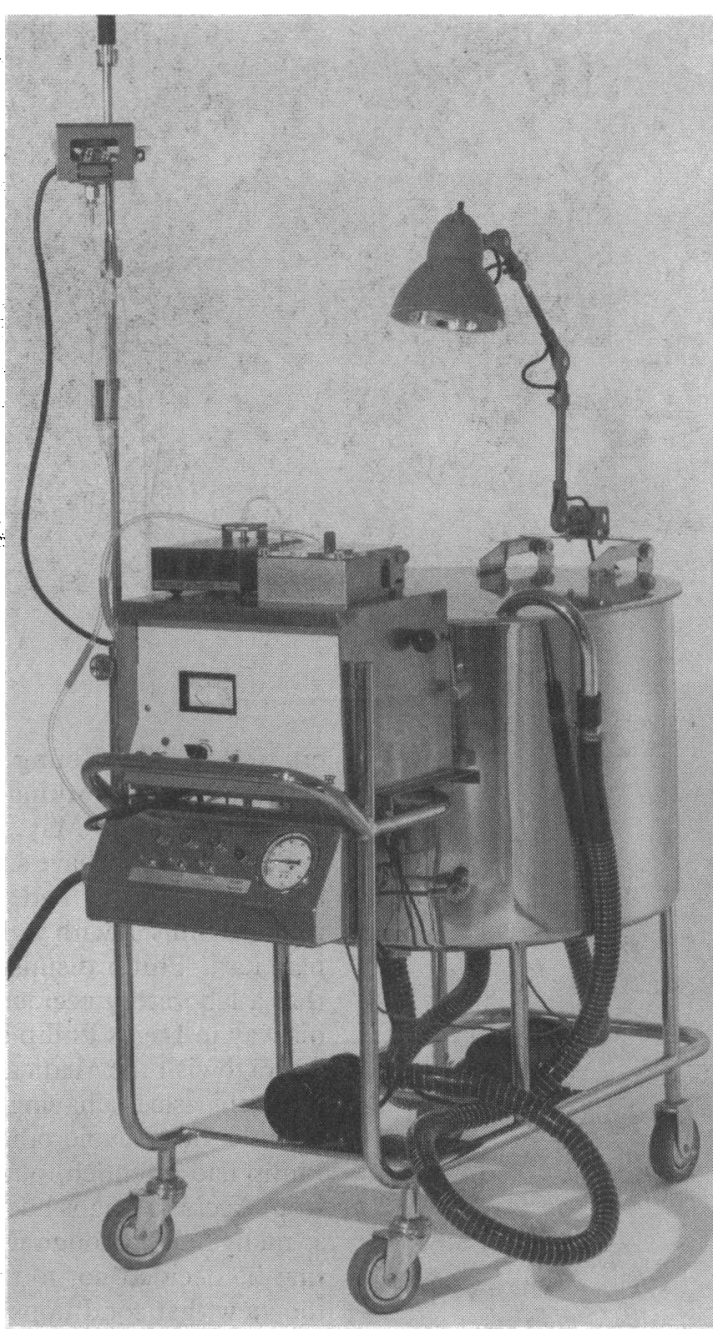

Dialysis system in use in the 1950s, manufactured by Baxter

would be in charge of the next acute admission. The patient was a man in his early 20 s who probably had end stage glomerular disease, although this had not been proved. The dialysis went well but it was the most traumatic one I have ever been in charge of. He constantly spat at me (and his aim was good) cursing "Bloody Limey," but such is the power of dialysis to correct uraemic estrangement that the next day he apologised profusely for his behaviour. He had an identical healthy twin and while I was returning to Britain on the Queen Elizabeth the daily newspaper recorded that he was the recipient of the first successful transplant between identical twins.

An additional bonus of my stay in Boston was a visit to Philadelphia to see the "pressure cooker dialyser" built by Inouye and Engelberg; little did I realise then that this was the forerunner of the Kolff twin coil unit that became the workhorse in dialysis units in the late 1950 s and early 1960 s.

\section{Leeds 1954-6}

At the end of 1954 there was little enthusiasm in Leeds for an artificial kidney, nor any space to house it. Nevertheless, I persuaded Professor Pyrah to write to the board of governors of the infirmary asking for a Kolff-Bingham machine. Surprisingly, we got it and also a blank cheque to cover its operating costs for two years. At the same time Professor Pyrah successfully negotiated with the Medical Research Council for the formation of a research unit with him as director and me as assistant director and adequate research laboratories and full financial support. But my troubles were far from over as I still had to convince Sir Harold 
Himsworth, secretary to the council, and Dr Herrod of the value of the artificial kidney - not an easy task as they had already been told that there was no place in British medicine for artificial kidneys. The interview lasted two hours, during which I described my experiences in Leeds and in Boston. This must have convinced them as Sir Harold dismissed me, saying, "Parsons, try it, but remember that the country is against you."

The problem of housing the artificial kidney was solved by Professor R E Tunbridge, who agreed to put it in his new metabolic ward and appointed his lecturer in medicine, Dr Brian McCracken, to help operate it.

\section{Operating the machine}

Initially, I took the machine into our laboratories to refamiliarise myself with its workings. After some help from the engineers of the infirmary we tested it by recirculating old blood, but unfortunately I forgot to use heparin and the whole machine clotted when the citrate was dialysed out.

Our first patient had acute tubular necrosis after major fractures of the legs and a blood urea concentration greater than $100 \mathrm{mmol} / \mathrm{l}$. All seemed to be going well, but after two hours the patient had a fatal major convulsion. I had never encountered this complication in Boston, but later we saw several similar examples, particularly in patients with severe uraemia, and we learnt to forestall it with small injections of thiopentone sodium. This condition was subsequently described by Professor Arthur Kennedy in a classic series of papers.

Despite this setback we carried on and also gave dialysis to several patients with chronic renal failure after strokes, heart failure, and so on; we abandoned treatment, however, when patients were known unequivocally to have irreversible renal disease. News of our activities spread, and we were soon treating patients referred from many parts of the United Kingdom. This began with some obstetric patients who, being eminently suitable for dialysis, were treated successfully.

In June 1957 we were asked to present our results at the annual meeting of the British Association of Urological Surgeons and set about trying to make them intelligible to surgeons. Professor Moore had shown that the negative protein balance increased with the severity of an injury. We could not undertake a protein balance because of the renal failure, but I had saved an aliquot of plasma (deep frozen) from each daily sample of blood, and by estimating blood urea concentration (as blood urea nitrogen concentration). in these as a batch we were able to divide the patients into three groups. In the first the daily rise in blood urea nitrogen concentration averaged less than $15 \mathrm{mg} / 100 \mathrm{ml} /$ day $(5.4 \mathrm{mmol} / \mathrm{l} / 24 \mathrm{~h})$ and the patients would have fared well on the dietary regimen alone. In the second the concentration rose between 15 and $30 \mathrm{mg} / 100 \mathrm{ml} /$ day $(5.4$ and $10.7 \mathrm{mmol} / 1 / 24 \mathrm{~h})$ and the patients were mainly pregnant and did better with dialysis in addition to the dietary regimen. In the last the average rise in blood urea nitrogen concentration was greater than $30 \mathrm{mg} / 100 \mathrm{ml}(10.7 \mathrm{mmol} / \mathrm{l}) / \mathrm{day}$ and the patients could not have survived without dialysis. These three groups were designated mild, moderate, or severe metabolic response, and I believe that this marked the turning point in attitudes towards dialysis in Britain because after this dialysis became not only acceptable but also highly desirable.

A flurry of activity followed as other dialysis centres were formed, mainly in the teaching hospitals. At first our workload in Leeds continued to increase as more hospitals heard about our efforts, but by 1960 the newer centres had started to ease the strain. Over the previous four years we had gradually become familiar with the natural course of acute tubular necrosis: we had started in 1956 in uncharted territory but by 1960 we could estimate in advance the course a patient was likely to follow.

1961 was an exciting year for me. I got the MD with distinction and membership of the Royal College of Physicians in Edinburgh and was appointed consultant physician in the infirmary. I had started a new discipline in the United Kingdom.

\section{Solutions to other problems}

Some of the problems we faced were intriguing. Professor Moore had shown that the metabolic response to injury was short lived in patients with normal renal function but prolonged in patients receiving dialysis. Therefore dialysis had to be prolonged. We soon noted that in dialysis there was a more complete removal of substances that diffuse quickly, such as urea, and called it the "differential correction of the uraemic state by dialysis." To try to correct this we tried giving dialysis for eight hours instead of six but neither the patients nor the staff could stand it. So reluctantly we started dialysis earlier in the development of uraemia, fearing that it would only increase the workload. The opposite occurred, for the waning metabolic response meant that fewer dialyses were required.

At one time severe pyrogen reactions occurred frequently, developing about 30 minutes after dialysis was started. They could not be explained. One day I said to our chief pharmacist that nylon did not absorb water; he replied that on the contrary it took up to $15 \%$ of its own weight in water. I therefore invested in an automatic pipette washer and after a dialysis we soaked all the non-disposable items in detergent for a day and then in running cold water overnight. The pyrogen reactions ceased forthwith.

In the early days of intermittent dialysis we had trouble with air coming out of the dialysis fluid and being transferred to the blood compartment, and this sometimes required dialysis to be halted. One day I was testing a new monitor unit and noticed air coming out of solution when I increased the negative pressure. I thought at first that there was a fault in the equipment but then the penny dropped and I realised that if we subjected the fluid to a negative pressure before it entered the dialyser our problem would be solved. And it was; this was probably the first positive de-airer to be used in a dialysis circuit.

\section{Sources of risks}

From the outset we were worried about the risk of transmitting hepatitis because of the large amount of blood used and the fact that Dr McCracken had contracted hepatitis from an intramuscular injection while in the United States. Syringes were one source of risk. In the 1950s wards had a communal syringe and needle, which were kept in spirit. I got my laboratory to prepare dry sterilised glass interchangeable syringes with new needles and continued this until the hospital took over the supply. Our other worry - the flowmeter - was particularly acute after we had given dialysis to a jaundiced patient. We were preparing to run cold water through it for 48 hours when someone offered to make us an autoclavable Perspex flowmeter, which he did with great success.

To reduce the risk of getting hepatitis from blood donors the blood transfusion service supplied us with blood from donors who had given blood many times and were thought to be free of hepatitis. When the public health laboratory at Colindale started limited testing for hepatitis B antigen we sent them samples of all the blood that had been used for retrospective 
testing (luckily all gave negative results) until our local laboratory was able to support us with prospective testing. We were one of the first units (perhaps the first) to take these precautions, which probably accounts for the absence of hepatitis in our unit. Even at the time of the Rosenheim committee only about a quarter of units were using blood that had been tested for hepatitis B antigen despite the number of cases of hepatitis that had occurred.

\section{European register}

In 1963 William Drukker from Amsterdam suggested that we should start a register of all patients being treated for end stage renal failure; he collected the data on dialysis and I collected data on transplants. It was the beginning of what is known as the European Dialysis and Transplant Association Register and one of the first attempts at medical audit. He left in 1970 and I gave the first combined report in 1971. The register continued and became a great success, eventually being taken over by Tony Wing.

\section{Conclusion}

In these memoirs I have tried to describe some of the problems that arose when dialysis was introduced in the United Kingdom. There is no space to follow through its use in chronic renal failure or for the many other anecdotes I would like to have told. I feel privileged to have participated in its introduction and would like to pay tribute to my five main teachers, all with international reputations but in four different disciplines-namely, Professors Pyrah and Spiers in Leeds, Professor Huggins in Chicago, and Professor Moore and Dr Merrill in Boston. They spent hours teaching and encouraging me, and their inspiration spurred me on.

\title{
Urinary retention and the lunisolar cycle: is it a lunatic phenomenon?
}

\author{
S R Payne, D J Deardon, G F Abercrombie, G L Carlson
}

Department of Urology,

St Mary's Hospital,

Portsmouth PO3 6AD

S R Payne, FRCS, senior urological registrar

D J Deardon, BM, senior house officer

G F Abercrombie, FRCS, consultant urologist

Department of Urology, Freeman Hospital,

Newcastle upon Tyne NE7 7DN

G L Carlson, MB, urological registrar

Correspondence to: $\mathrm{Mr} \mathrm{S} \mathrm{R}$ Payne, Department of Urology, Manchester Royal Infirmary, Manchester M13 9WL.

BrMed f 1989;299:1560-2
Abstract

Objective-To determine whether a relation between urinary retention and temporal rhythms exists.

Design-Retrospective analysis of patients presenting over three years.

Setting-Urology departments in two hospitals.

Patients -815 Patients presenting as emergency admissions with urinary retention and requiring immediate decompression of the bladder.

Main outcome measures-Calendar date of each admission to determine circadian, monthly, and seasonal periodicity.

Results-No association was found between urinary retention and circadian, monthly, or seasonal rhythms. A significantly higher $(\mathbf{p}<0 \cdot 001)$ incidence of urinary retention was observed during the new moon in comparison with other phases of the lunar cycle.

Conclusions-Urinary retention is periodic in nature. This should be considered when the workload of a specialist urological department is organised.

\section{Introduction}

Retention of urine is common. Benign fibromuscular hyperplasia, which affects up to a quarter of the male population, ${ }^{1}$ is the most common cause. The immediate cause of this complication is unclear as most men will have a history of longstanding obstruction of outflow before presenting urgently. Identification of factors likely to precipitate acute urinary rentention is important as a pre-emptive operation may reduce the mortality from emergency prostatectomy..$^{23}$

The development of urinary retention in benign prostatic hypertrophy seems to be complex, having a non-fluctuant mechanical component due to adenomatous enlargement and a variable dynamic element secondary to autonomically regulated tone within the capsular muscle. ${ }^{4}$ Various organ systems including the autonomic nervous system can be influenced by external environmental factors, ${ }^{5-7}$ and rhythmic activity, particularly lunisolar periodicity, has a distinct bearing on the homoeostatic regulation of compartmental fluid shifts and micturition in lower life forms ${ }^{89}$ We studied whether non-biological environmental factors, which may be responsible for altered sympathetic activity or an increased water load on the failing bladder, could precipitate detrusor decompensation. We examined true periodic phenomena such as daily (circadian), monthly, seasonal, and lunar rhythms and social influences that alter fluid throughput, such as weekend and festive drinking.

\section{Patients and methods}

We analysed retrospectively all male patients presenting urgently with urinary outflow obstruction and requiring immediate bladder decompression between August 1985 and July 1988 in Portsmouth. We studied the calendar dates of presentation to determine the circadian, monthly, and seasonal periodicity, lunar relations being determined by reference to standard observatory charts.

Circadian presentations were measured as the number of cases of urinary retention occurring on each day of the week and analysed as the total number presenting on that day on an annual basis (a solar year). To determine whether there was any difference in the number of cases of retention during weekdays and weekends the total number of presentations a day on weekdays (Monday to Thursday) and weekends (Fridays to Sundays) were calcuated for each solar year and compared.

Monthly presentations were measured per calendar month and expressed as a total over a solar year. Seasonal presentations were taken from the monthly figures and expressed as a total of seasonal presentations per solar year. The seasons were defined as follows: winter-January to March; spring-April to June; summer-July to September; and autumn-October to December. The admissions for July 1988 were summed with those from August and September 1985 to complete a nominal season.

Lunar relations were determined by comparing the date of admission with the phase of the moon according to the United States Naval Observatory. The four 